utility in patients with suspected microlithiasis. Dig Dis $S_{c i} 1992 ; 37$ $116-20$.

18 Davidson BR, Neoptolemos JP, Carr-Locke DL. Endoscopic sphincterotomy for common bile duct calculi in patients with gallbladder in situ considered unfit for surgery. Gut 1988; 29: 114-20.

19 Vaira D, Ainley C, Williams S, et al. Endoscopic sphincterotomy in 1000 consecutive patients. Lancet 1989; ii: 431-34.

20 Siegel JH, Safrany L, Ben Zvi JS, et al. Duodenic sphincterotomy in patients with gallbladders in situ: report of a series of 1272 patients. Am 7 Gastroenterol 1988; 11: 1255-58.

21 Rösch T, Dittler HJ, Fockens P, Yasuda K, Lightdale C. Major complications of endoscopic ultrasonography: results of a survey of 42105 cases. Gastrointest Endosc 1993; 39: 341.
22 Neuhaus H, Feussner H, Ungeheur A, Hoffman W, Siewert JR, Classen M. Prospective evaluation of the use of endoscopic retrograde cholangiography prior to laparoscopic cholecystectomy. Endoscopy 1992; 24: 745-49.

23 Neoptolemos JP, London NJ, James D, Carr-Locke DL, Bailey IA, Fossard DP. Controlled trial of urgent endoscopic retrograde cholangiopancreatography and endoscopic sphincterotomy versus conservative treatment for acute pancreatitis due to gallstones. Lancet 1988; ii: 979-83.

24 Lai ECS, Mok FPT, Tan ESY, et al. Endoscopic biliary drainage for severe acute cholangitis. $N$ Engl 7 Med 1992; 326: 1582-86.

25 Cotton PB. Endoscopic management of bile duct stones (apples and oranges). Gut 1984; 25: 587-97.

\title{
Randomised trial of excimer laser angioplasty versus balloon angioplasty for treatment of obstructive coronary artery disease
}

\author{
Yolande E A Appelman, Jan J Piek, Sipke Strikwerda, Jan G P Tijssen, Pim J de Feyter, George K David, \\ Patrick W Serruys, James $R$ Margolis, Mark J Koelemay, Eline W J Montauban van Swijndregt, Jacques J Koolen
}

\section{Summary}

Background Excimer laser coronary angioplasty is reported to give excellent procedural results for treatment of complex coronary lesions, but this method has not been compared with balloon angioplasty in a randomised trial.

Methods Patients $(\mathrm{n}=308)$ with stable angina and coronary lesions longer than $10 \mathrm{~mm}$ on visual assessment were included. 151 patients (158 lesions) were assigned randomly to laser angioplasty and 157 (167 lesions) to balloon angioplasty. The primary clinical endpoints were death, myocardial infarction, coronary bypass surgery, or repeat coronary angioplasty of the randomised segment during 6 months of follow-up. The primary angiographic end-point was the minimal lumen diameter at follow-up in relation to the baseline value (net gain), as determined by quantitative coronary angiography.

Findings Laser angioplasty was followed by balloon angioplasty in $98 \%$ of procedures. The angiographic success rate was $80 \%$ in patients treated with laser angioplasty compared with $79 \%$ in patients treated with balloon angioplasty. There were no deaths. Myocardial infarction, coronary bypass surgery, and repeat angioplasty occurred in $4.6 \%, 10.6 \%$, and $21.2 \%$, respectively, of the patients in the laser angioplasty group compared with $5.7 \%, 10.8 \%$, and $18.5 \%$ of the balloon angioplasty group. Net mean (SD) gain in minimal lumen diameter was 0.40 $(0.69) \mathrm{mm}$ in patients treated with laser angioplasty and $0.48(0.66) \mathrm{mm}$ in those treated with balloon angioplasty $(p=0.34)$. The restenosis rate $(>50 \%$ diameter stenosis) was $51.6 \%$ in the laser angioplasty group versus $41.3 \%$ in the balloon angioplasty group $(p=0 \cdot 13)$.

University of Amsterdam Department of Cardiology

(Y E A Appelman MD, J J Piek MD, G K David MD) and Department of Clinical Epidemiology and Biostatistics (Prof J G P Tijssen PhD, $M J$ Koelemay MD) Academic Medical Centre, Meibergdreef 9, 1105 AZ Amsterdam, Netherlands; Thoraxcenter, Rotterdam, Netherlands (S Strikwerda MD, P J de Feyter MD, P W Serruys MD, E W J Montauban van Swijndregt); the Miami Heart Institute, Miami, USA ( $J$ R Margolis MD); and Catharina Hospital, Eindhoven, Netherlands ( $J$ J Koolen MD)

Correspondence to: Dr Jan J Piek
Interpretation Excimer laser angioplasty followed by balloon angioplasty provides no benefit additional to balloon angioplasty alone with respect to the initial and long-term clinical and angiographic outcome in the treatment of obstructive coronary artery disease.

Lancet 1996; 347: 79-84

\section{Introduction}

Excimer laser coronary angioplasty (ELCA) is one technique used for treatment of obstructive coronary artery disease. The excimer laser system exhibits favourable characteristics for ablation of atherosclerotic tissue compared with other laser devices because of its small penetration depth and the induction of limited damage to the vascular wall. ${ }^{1-4}$ Compared with results after balloon angioplasty, ${ }^{5}$ prospective non-randomised studies of $\mathrm{ELCA}^{6-8}$ showed a substantial improvement in primary success rate and procedural complications in patients with complex coronary lesions. These promising results warranted a randomised trial to establish the role of laser angioplasty as an alternative approach in the treatment of obstructive coronary artery disease. Most patients considered suitable for coronary angioplasty have long $(>10 \mathrm{~mm})$ coronary lesions. These considerations led us to undertake a randomised trial to evaluate initial and long-term clinical and angiographic outcome of ELCA compared with balloon angioplasty in patients with long coronary lesions.

\section{Methods}

\section{Selection of patients}

After completion of a pilot phase including 71 patients, ${ }^{9}$ the multicentre Amsterdam-Rotterdam (AMRO) trial was started in September, 1991, and completed in November, 1993. Based upon the results of nonrandomised studies of ELCA, we expected the primary procedural success rate after ELCA to be greater than $85 \%$ and less than $70 \%$ after balloon angioplasty. Thus, with an alpha-error of 0.05 and a beta error of $0.20,120$ patients with complete follow-up were required in each treatment group. 300 patients were considered necessary for inclusion taking into account that $20 \%$ of the patients were not eligible for follow-up angiography. All patients (either with single or multivessel disease) with stable angina pectoris, coronary lesions longer than $10 \mathrm{~mm}$ on visual assessment, and total or functional 
occlusions (thrombolysis in myocardial infarction [TIMI] flow grade 0 or 1$)^{11}$ who were suitable for coronary angioplasty were screened for inclusion in the trial. Clinical exclusion criteria were: unstable angina, myocardial infarction within the previous 2 weeks, a life expectancy of less than 1 year, and factors that made clinical or angiographic follow-up difficult. Angiographic exclusion criteria were: intended angioplasty of a venous bypass graft, unprotected left main disease, extreme tortuosity of the vessel, highly eccentric lesions, vessels with ostial lesions, angulated lesions of more than $45^{\circ}$, bifurcation lesions, aortaostial lesions, lesions with angiographic evidence of a thrombus or dissection, and total occlusions with a low likelihood of passage with a guide wire. ${ }^{11}$ The protocol was approved by the institutional review boards of the participating centres.

\section{Randomisation}

Patients were assigned randomly by telephone from a central office to laser angioplasty or balloon angioplasty after eligibility had been established and written informed consent obtained. Lesions suitable for balloon angioplasty only were indicated before the randomisation in patients with multiple lesions. All coronary lesions in a patient who fulfilled the selection criteria were treated according to the same treatment allocation.

\section{Laser angioplasty and balloon angioplasty}

Patients' anti-anginal medication was continued until the procedure. A calcium antagonist (nifedipine $20 \mathrm{mg}$ three times a day) was added during in-hospital stay. Acetyl salicylic acid (250-500 mg daily) was given a day before the procedure and continued for 6 months afterwards. The excimer laser systems (wavelength $308 \mathrm{~nm}$ ) used were: the Dymer 200+ (Advanced Interventional Systems Inc, Irvine, CA, USA), with a pulse duration of $210 \mathrm{~ns}$ and a repetition rate of $20 \mathrm{~Hz}$, delivered by multifibre over wire laser catheters with a diameter of $1.3,1 \cdot 6$, or $2.0 \mathrm{~mm}$, at a fluence of $45-65 \mathrm{~mJ} / \mathrm{mm}^{2}$; and the CVX-300 system (Spectranetics, Colorado Springs, CO, USA), which emits a pulse duration of $135 \mathrm{~ns}$ at a repetition rate of $25 \mathrm{~Hz}$, delivered by $1.4,1.7$ or $2.0 \mathrm{~mm}$ laser catheters, with a similar fluence. The $1.3 \mathrm{z} \mathrm{mm}$ laser catheter was used after its introduction in 1992. The $1 \cdot 3 / 1.4 \mathrm{~mm}$ laser catheter was used for vessels with diameter of $1 \cdot 8-2 \cdot 3 \mathrm{~mm}, 1 \cdot 6 / 1 \cdot 7 \mathrm{~mm}$ laser catheter for vessels with a diameter of $2 \cdot 3-3.0 \mathrm{~mm}$, and $2.0 \mathrm{~mm}$ laser catheter for vessels with a diameter of $3.0 \mathrm{~mm}$ or more.

Cardiac catheterisation in all patients was by the percutaneous femoral approach. Heparin was administered intravenously to maintain the activated clotting time at more than $400 \mathrm{~s}$ and was continued for at least $12 \mathrm{~h}$ after the procedure. After crossing the lesion with the guide wire, the laser catheter was advanced at a speed of about $1 \mathrm{~mm} / \mathrm{s}$. A larger laser catheter was used if the angiographic result was unsatisfactory after one passage of the laser catheter. Additional balloon angioplasty was done to optimise the angiographic result. Serum creatine kinase myocardial band concentration was measured routinely within $12 \mathrm{~h}$ after the initial procedure.

\section{Quantitative coronary angiography}

Quantitative coronary angiography, before and after the procedure and at 6 months' follow-up, was done after administration of $0 \cdot 1-0 \cdot 3 \mathrm{mg}$ of nitroglycerin or $1-3 \mathrm{mg}$ of isosorbine dinitrate by the intracoronary route. The angiograms were analysed, in a central laboratory with the computer-assisted cardiovascular angiography analysis system (CAAS) for determination of the interpolated reference diameter, the minimal lumen diameter, and the percentage diameter stenosis. ${ }^{12}$ Lesion length was determined by the maximal lesion length between the crossing point of the computerised contour detection line and the interpolated reference diameter line. If a revascularisation procedure involving the treated segment had been done before the angiography at 6 months, the most recent angiogram obtained before this intervention was used as the follow-up angiogram regardless of the timing of the second intervention. If the time from intervention to follow-up

\begin{tabular}{|c|c|c|}
\hline & ELCA & $\begin{array}{l}\text { Balloon } \\
\text { angloplasty }\end{array}$ \\
\hline Number of patlents & 151 & 157 \\
\hline \multicolumn{3}{|l|}{ Clinical characteristics } \\
\hline Mean (range) age (yr) & $58 \cdot 1(32-83)$ & $59 \cdot 4(35-79)$ \\
\hline Sex (male/female) & $115 / 36$ & $114 / 43$ \\
\hline \multicolumn{3}{|l|}{ Smoking status } \\
\hline Never & 41 & 50 \\
\hline Previous & 74 & 68 \\
\hline Current & 33 & 36 \\
\hline Unknown & 3 & 3 \\
\hline Diabetes mellitus & 15 & 20 \\
\hline \multicolumn{3}{|l|}{ Previous conditions } \\
\hline History of hypertension & 57 & 50 \\
\hline History of hypercholesterolaemı & 58 & 59 \\
\hline History of stroke & 4 & 5 \\
\hline History of peripheral vascular disease & 9 & 14 \\
\hline Myocardial Infarction & 70 & 68 \\
\hline Coronary artery bypass grafting & 10 & 13 \\
\hline Balloon angioplasty & 16 & 25 \\
\hline \multicolumn{3}{|l|}{ Exertional angına (CCS class*) } \\
\hline 1 & 11 & 8 \\
\hline II & 44 & 49 \\
\hline III & 82 & 86 \\
\hline IV & 14 & 14 \\
\hline Non exertional angına & 77 & 81 \\
\hline Mixed angina & 76 & 80 \\
\hline \multicolumn{3}{|l|}{ Medication at screenıng } \\
\hline Nitrates & 95 & 108 \\
\hline Ca-antagonists & 122 & 133 \\
\hline Beta-blockers & 120 & 113 \\
\hline Monotherapy & 25 & 20 \\
\hline Double-therapy & 57 & 65 \\
\hline Triple-therapy & 66 & 68 \\
\hline No therapy & 3 & 4 \\
\hline \multicolumn{3}{|l|}{ Extent of coronary artery disease } \\
\hline One-vessel disease & 83 & 79 \\
\hline Two-vessel disease & 51 & 63 \\
\hline Three-vessel disease & 17 & 15 \\
\hline Number of lesions & 158 & 167 \\
\hline
\end{tabular}

\section{Angiographic characteristics}

Location of lesion

Right coronary artery

Left anterior descending

Left circumflex

Type of Iesion†

A

B2

Ulcerated

Multiple irregularitıes

Calcified

Eccentric

Tandem

Length by visual assessment (mm)

$<10$

$10-20$

$>20$

Unknown

Grade of perfusion‡

0

I

III

$\begin{array}{rr}56 & 61 \\ 61 & 64 \\ 41 & 42 \\ & \\ 1 & 0 \\ 0 & 2 \\ 83 & 71 \\ 74 & 94 \\ 53 & 55 \\ 83 & 97 \\ 33 & 39 \\ 100 & 104 \\ 18 & 26 \\ & \\ 1 & 3 \\ 122 & 109 \\ 33 & 44 \\ 2 & 11 \\ & \\ 26 & 27 \\ 23 & 27 \\ 27 & 24 \\ 85 & 89\end{array}$

*Accordıng to classificatıon of Canadian Cardiovascular Society:13 taccording to modified American College of Cardiology/American Heart Association task force criteria, ${ }^{14}$ faccordıng to TIMI-study group. ${ }^{10}$

Table 1: Base-line clinical and angiographic characteristics of 308 patients included in the intention-to-treat analysis

angiography was less than 3 months and no second intervention was performed, the patient was asked to undergo angiography again after 6 months. In the absence of a second angiogram at 6 months, the angiogram obtained most recently within the previous 3 months was used.

\section{Clinical and angiographic follow-up}

Patients were seen after 1 and 6 months for an interview, physical examination, and electrocardiogram. Follow-up coronary angiography was done after 6 months. Repeat intervention was 
performed based on recurrent symptoms of angina and/or objective evidence of myocardial ischaemia and a diameter stenosis of more than $50 \%$ on visual assessment.

\section{End-points}

Primary clinical end-points were the occurrence of any of the following events during a 6 month ( \pm 1 month) follow-up: cardiac death, myocardial infarction (based on the presence of at least two of the following: typical chest pain and/or a serum rise of more than twice the normal upper limit of the creatine kinase myocardial band level and/or new pathological Q-wave formation on the electrocardiogram), coronary bypass surgery, or a second angioplasty because of recurrent symptoms of angina and/or objective evidence of myocardial ischaemia by positive exercise testing related to the randomised segment. Coronary bypass surgery was defined to include emergency (within $12 \mathrm{~h}$ after the procedure) or elective bypass surgery. All the clinical events were reviewed by the critical-event committee, which was unaware of the treatment assignment.

Primary angiographic end-point was the minimal lumen diameter at the treated coronary site at 6 months follow-up relative to the baseline value before the procedure (net gain). Secondary end-points were: (1) laser success defined as a more than $20 \%$ reduction in diameter stenosis after laser angioplasty only on visual assessment; (2) angiographic success defined as a less than $50 \%$ residual stenosis at the end of the procedure on visual assessment; (3) acute gain defined as the minimal lumen diameter at the treated coronary site at the end of the procedure relative to the baseline value; (4) functional class at 6 months according to the classification of the Canadian Cardiovascular Society; ${ }^{13}$ (5) the percent diameter stenosis at the treated coronary site at 6 months' follow-up relative to the baseline value (net gain in percentage diameter stenosis); (6) restenosis rate defined as a more than $50 \%$ diameter stenosis at the treated coronary site at 6 months' follow-up angiography as determined by automated contour detection analysis; and (7) late loss defined as the minimal lumen diameter at the treated site at 6 months' follow-up relative to the minimal lumen diameter after the procedure.

\section{Statistical analysis}

Continuous variables (age, reference diameter, lesion length, percentage diameter stenosis, and minimal lumen diameter) were expressed as mean (SD) and were compared with the unpaired $t$ test. Chi-squared analysis and Fisher's exact test for two by two tables were used to compare dichotomous variables. Clinical events and angiographic complications were compared by relative risk (RR) and 95\% confidence interval. A p value less than 0.05 was considered statistically significant.

\section{Results}

\section{Patient characteristics and randomisation}

313 consecutive patients (330 lesions) were randomly assigned to ELCA (155 patients/162 lesions) or balloon angioplasty (158 patients/168 lesions). In five patients (four assigned to laser angioplasty, one to balloon angioplasty) the randomised segment was not treated. Of these five patients, one withdrew his informed consent and received balloon angioplasty. Two patients received no coronary intervention because the randomised segment showed a non-significant stenosis on the preprocedural angiogram. One patient was randomised twice. The randomised segment was not treated in one patient due to emergency coronary bypass surgery after treatment of a non-randomised segment. These five patients were not included in the final analysis since there was no intention for treatment according to randomisation.

Clinical and angiographic baseline characteristics of the remaining 308 patients were similar and are shown in table 1. Approximately half of the patients had multivessel disease and $50 \%$ had experienced a previous myocardial infarction. One third of the randomised coronary segments were total or functional coronary occlusions (TIMI 0 or 1 ).

158 lesions (151 patients) were randomly assigned to ELCA. ELCA could not be done during 25 procedures (25 patients) because of inability to cross the coronary lesion with any guide wire (16 lesions), or cross-over to balloon angioplasty (in total nine lesions: five because of inability to pass the guide wire, three due to technical failure of the laser system, and one because of presumed risk of perforation). Of the remaining 133 lesions, 130 were treated with additional balloon angioplasty to obtain an optimal angiographic result. Standalone laser angioplasty was done with three lesions ( $2 \%)$. In 89 of the $133(67 \%)$ treated lesions, a laser catheter not larger than $1.3 / 1.4 \mathrm{~mm}$ was used. In 19 lesions more than one laser catheter was used.

167 lesions (157 patients) were randomly assigned to balloon angioplasty. Balloon angioplasty was not done during 22 procedures because the lesion could not be crossed with a guide wire. In two patients the lesion could not be crossed with the balloon; one of these was successfully treated with laser angioplasty only and one with laser angioplasty followed by balloon angioplasty. The remaining 143 lesions were treated with balloon angioplasty only.

\section{Procedural results}

The intention-to-treat analysis yielded a laser success by visual assessment in 68\% (107 lesions) of the 158 lesions randomly assigned to ELCA. The angiographic success rate by visual assessment was $80 \%$ (126 lesions) in patients treated with ELCA compared with $79 \%$ (132 lesions) in patients treated with balloon angioplasty. The angiographic success rate by quantitative coronary angiography yielded similar results $(80 \%$ in patients assigned to ELCA compared with $78 \%$ in patients assigned to balloon angioplasty).

The per protocol analysis yielded a success rate of $81 \%$ after ELCA, which increased to $91 \%$ after additional balloon angioplasty in patients allocated to ELCA compared with an angiographic success rate of $92 \%$ in

\begin{tabular}{|c|c|c|c|c|}
\hline & $\begin{array}{l}\text { ELCA } \\
(n=151)\end{array}$ & $\begin{array}{l}\text { Balloon } \\
\text { angloplasty } \\
(\mathrm{n=157})\end{array}$ & $\begin{array}{l}\text { Relative risk } \\
(95 \% \mathrm{CI})\end{array}$ & $\mathbf{p}$ \\
\hline Death & 0 & 0 & . & . \\
\hline Myoardial infarction & $7(4 \cdot 6)$ & $9(5 \cdot 7)$ & $0 \cdot 81(0 \cdot 31-2 \cdot 12)$ & 0.67 \\
\hline Q-wave & $4(2 \cdot 6)$ & $3(1.9)$ & $1.39(0.32-6.10)$ & 0.72 \\
\hline Periprocedural & $2(1 \cdot 3)$ & $2(1 \cdot 3)$ & $1.04(0.15-7.29)$ & 0.97 \\
\hline Follow-up & $2(1 \cdot 3)$ & $1(0 \cdot 6)$ & $2.08(0.19-22.70)$ & 0.54 \\
\hline Non-Q-wave & $3(2 \cdot 0)$ & $6(3.8)$ & $0.52(0.13-2.04)$ & 0.50 \\
\hline Perıprocedural & $3(2 \cdot 0)$ & $3(1.9)$ & $1.04(0.21-5.07)$ & 0.96 \\
\hline Follow-up & 0 & $3(1.9)$ & $0.15(0.01-2.85)$ & 0.09 \\
\hline $\begin{array}{l}\text { Coronary artery bypass } \\
\text { grafting }\end{array}$ & $16(10 \cdot 6)$ & $17(10 \cdot 8)$ & $0.98(0.51-1.87)$ & 0.95 \\
\hline Periprocedural & $7(4 \cdot 5)$ & $3(1.9)$ & $2.43(0.64-9.21)$ & 0.18 \\
\hline Follow-up & $9(6 \cdot 0)$ & $14(8.9)$ & $0.67(0.30-1.50)$ & 0.32 \\
\hline Repeat angioplasty & $32(21 \cdot 2)$ & $29(18.5)$ & $1.15(0.73-1.80)$ & 0.55 \\
\hline Periprocedural & $2(1 \cdot 3)$ & $3(1 \cdot 9)$ & $0.69(0.12-4.09)$ & 0.68 \\
\hline Follow-up & $30(19.9)$ & $26(16 \cdot 6)$ & $1.20(0.75-1.93)$ & 0.45 \\
\hline $\begin{array}{l}\text { Primary clinical } \\
\text { endpoint* }\end{array}$ & $50(33 \cdot 1)^{*}$ & $47(29 \cdot 9)$ & $1 \cdot 11(0 \cdot 80-1 \cdot 54)$ & 0.55 \\
\hline
\end{tabular}

*Death, myocardial infarction, coronary artery bypass graftıng, or repeat angioplasty. Table 2: Number (\%) clinical events during the procedure and 6 months' follow-up 


\begin{tabular}{|c|c|c|c|c|}
\hline & ELCA & $\begin{array}{l}\text { Balloon } \\
\text { angioplasty }\end{array}$ & $\begin{array}{l}\text { Difference } \\
(95 \% \mathrm{CI})\end{array}$ & $\mathbf{p}$ \\
\hline Number of lesions & 124 & 126 & . & . \\
\hline $\begin{array}{l}\text { Reference dlameter* } \\
(\mathbf{m m})\end{array}$ & $2.51(0.47)$ & $2.47(0.59)$ & . & . \\
\hline Length (mm) & $1769(5.58)$ & $18 \cdot 82(7 \cdot 15)$ & & . \\
\hline \multicolumn{5}{|l|}{ Diameter stenosis (\%) } \\
\hline Before angıoplasty & $68 \cdot 5(18 \cdot 3)$ & $68.9(18.6)$ & 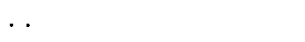 & \\
\hline After angioplasty & $37 \cdot 6(10 \cdot 3)$ & $37.9(8.9)$ & $-0.4(-2.8$ to 2.0$)$ & 0.76 \\
\hline At follow-up & $56 \cdot 1(23 \cdot 3)$ & $52 \cdot 6(23 \cdot 4)$ & $3.4(-2.4$ to 9.3$)$ & 0.25 \\
\hline Restenosis (\%) & $51 \cdot 6$ & $41 \cdot 3$ & $10 \cdot 3(-2 \cdot 0$ to $22 \cdot 6)$ & 0.13 \\
\hline \multicolumn{5}{|l|}{$\begin{array}{l}\text { Minimal lumen } \\
\text { diameter (mm) }\end{array}$} \\
\hline Before ang!oplasty & $077(0.44)$ & $0.77(0.47)$ & $\cdots$ & $\cdots$ \\
\hline After angloplasty & $1.69(0.41)$ & $1.59(0.34)$ & $0.10(0.01$ to 0.19$)$ & 0.05 \\
\hline At follow-up & $1.17(0.71)$ & $1.25(0.68)$ & $-0.08(-0.25$ to 0.93$)$ & 0.34 \\
\hline Net gain† (mm) & $0.40(0.69)$ & $0.48(0.66)$ & $-0.08(-0.25$ to 0.09$)$ & 0.34 \\
\hline Acute gain $\ddagger$ & $0.92(0.53)$ & $0.82(0.50)$ & $0.10(-0.03$ to 0.23$)$ & 0.15 \\
\hline Late loss\$ (mm) & $0.52(0.70)$ & $0.34(0.62)$ & $0.18(0.15$ to 0.35$)$ & 0.04 \\
\hline
\end{tabular}

Figures are mean (SD) unless indicated.

* Referance values are interpolated diameters of normal vessels: tmınımal lumen diameter (MLD) at follow-up minus MLD before inıtial procedure; $\ddagger M L D$ after initıa procedure minus MLD before initıal procedure; $\$ M L D$ after initıal procedure minus MLD at follow-up.

Table 3: Quantitative analysis

patients allocated to balloon angioplasty (RR 0.99, 95\% CI $0.92-1 \cdot 06 ; p=0 \cdot 69$ ).

There were no deaths. The incidence of $\mathrm{Q}$-wave and non-Q-wave myocardial infarctions was similar in both groups (table 2). Most non-Q-wave myocardial infarctions were small in both groups (maximal creatine kinase-myocardial band concentration $<20 \mathrm{U} / \mathrm{L}$ ).

Seven patients $(4.5 \%)$ randomly assigned to ELCA required emergency coronary bypass surgery for the following reasons: severe dissection of the randomised segment (four patients, two of whom were treated with stenting as a bridge to coronary bypass surgery), perforation of the randomised segment (one patient), extravasation of contrast (one patient), and unstable angina (one patient). Emergency coronary bypass surgery was required in three patients $(1.9 \%)$ randomly assigned to balloon angioplasty due to the occurrence of a severe dissection.

Intimal dissections after completion of the procedure occurred in 74 lesions $(46.8 \%)$ in the patients treated with ELCA. Most of these dissections (91\%) were minor: type $A$ in 27 lesions, type $B$ in 22 lesions, and type $C$ in 18 lesions. ${ }^{15}$ The dissection rate was similar in patients treated with balloon angioplasty $(54.5 \%$ [91 lesions] of patients) with $90 \%$ of dissections being minor: type $\mathrm{A}$ in 33 lesions, type $B$ in 37 lesions, and type $C$ in 12 lesions. The procedure was complicated by coronary spasm in seven patients treated with ELCA and in two patients treated with balloon angioplasty (RR 3.70, 95\% CI $0.78-17 \cdot 54 ; p=0 \cdot 1)$. Coronary perforation resulting in haemodynamic deterioration occurred in one patient in the ELCA group. This complication did not occur in the balloon angioplasty group. The incidence of transient occlusions of the randomised segment was significantly higher in patients allocated to ELCA (ten patients) than in those allocated to balloon angioplasty (one patient) $(10 \cdot 57,1 \cdot 37-81 \cdot 62 ; \mathrm{p}=0.005)$.

\section{Clinical and angiographic outcomes}

Clinical follow-up was complete in $98 \%$ of patients. A primary clinical end-point was reached in 50 patients $(33.1 \%)$ treated with ELCA versus 47 patients $(29.9 \%)$

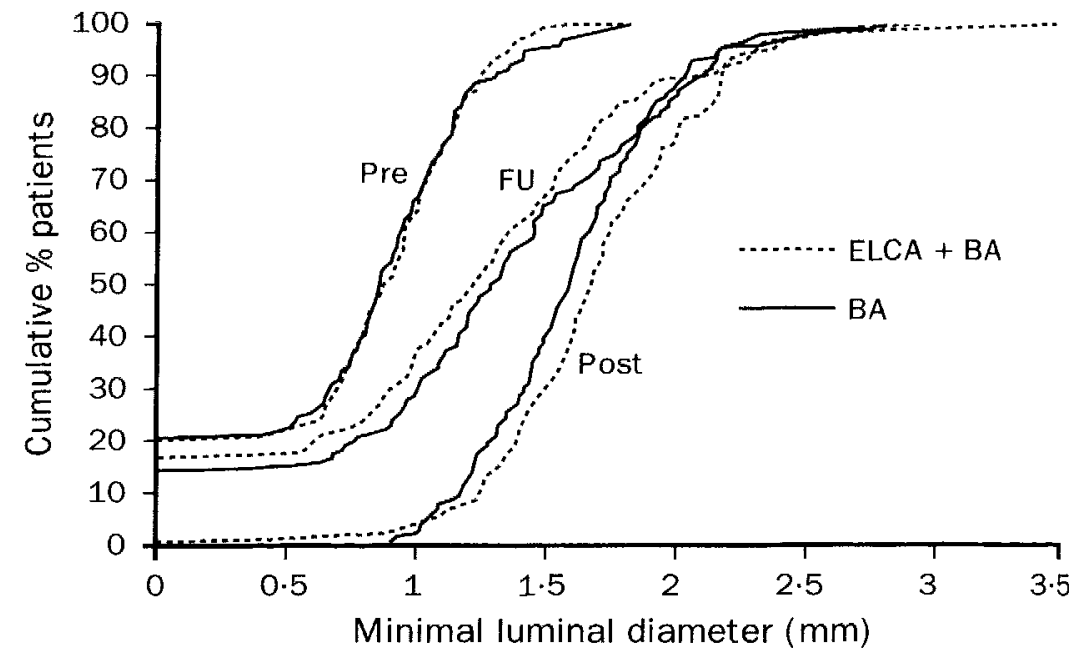

Figure: Cumulative frequency distribution curves

Minimal luminal diameters are shown before the initial intervention (Pre), after the initial intervention (Post), and at follow-up angiography (FU) for 151 patients treated with ELCA followed by additional balloon angioplasty $(E L C A+B A)$ and 157 patients treated with balloon angioplasty (BA).

treated with balloon angioplasty. The incidences of myocardial infarction, coronary bypass surgery, and repeat angioplasty were similar in both groups (table 2).

Of the 151 patients randomly assigned to ELCA, 91 patients had no angina, 17 patients were graded as functional class I, 31 patients as class II, 11 patients as class III, and one patient as class IV according to the Canadian Cardiovascular Society classification criteria $^{13}$ after 6 months' follow-up. Of the 157 patients randomly assigned to balloon angioplasty, 94 patients had no angina, 17 patients were graded as functional class I, 27 patients as class II, 17 patients as class III, and two patients as class IV after 6 months' follow-up.

Follow-up angiography was not requested in 22 of the 151 patients in the ELCA group due to failure of the initial procedure or coronary bypass surgery. Repeat angiography was performed in 120 of the remaining 129 patients (93\%). Follow-up angiography in the balloon angioplasty group was requested in 131 of the 157 patients. Repeat angiography was done in 123 of these patients $(91 \%)$.

The net gain in minimal lumen diameter was similar in both groups (table 3 ). The net gain in the ELCA group was the result of a small, but non-significant, increase in the acute gain minus a significant greater late loss compared with the balloon angioplasty group. The cumulative distribution of the minimal lumen diameter is shown in the figure. The net mean (SD) gain in diameter stenosis was $12 \cdot 4(25 \cdot 1) \%$ in the ELCA group versus $16 \cdot 2$ $(25.9) \%$ in the balloon angioplasty group (difference $-3.9 \%, 95 \%$ CI $-10 \cdot 2$ to $2 \cdot 5 ; \mathrm{p}=0 \cdot 2$ ). The incidence of restenosis was $51.6 \%$ in the ELCA group compared with $41.3 \%$ in the balloon angioplasty group $(p=0 \cdot 13)$.

\section{Discussion}

The purpose of this randomised study was to compare the clinical and angiographic outcome of ELCA versus balloon angioplasty in the treatment of longer $(>10 \mathrm{~mm})$ coronary lesions. The more recent data from ELCA registries indicate an increased use of additional balloon angioplasty, which is consistent with the results of our study. ${ }^{16-18}$ ELCA was followed by balloon angioplasty in $98 \%$ of procedures and therefore this trial in fact comprises a comparison between combined ELCA and balloon angioplasty versus balloon angioplasty only. 
We have shown that ELCA and balloon angioplasty for the treatment of obstructive coronary artery disease yield similar initial and long-term clinical and angiographic outcomes in a selected cohort of patients with stable angina and coronary lesions longer than $10 \mathrm{~mm}$.

Clinical outcome for primary clinical and angiographic end-points were similar in both groups. With respect to the differences observed, there was a significantly higher rate of transient occlusions in the ELCA group compared with the balloon angioplasty group $(6 \cdot 3 \%$ vs $0.6 \%)$. This may be explained by a response of the vascular wall due to the mechanical effects caused by a fast expanding and imploding vapour bubbles generated during ELCA. ${ }^{19,21}$ In general, this complication can be dealt with by administration of intracoronary nitroglycerin and additional balloon angioplasty.

Furthermore, there was a significant greater late loss in minimal lumen diameter in the ELCA group compared with the balloon angioplasty group. This finding may be related to an accelerated degree of neointimal response due to the mechanical effects of rapid vapour bubble formation during laser application or a negative influence on the geometric remodelling process after intracoronary interventions. ${ }^{21,22}$ The greater late loss in minimal lumen diameter resulted in a higher restenosis rate after ELCA$51.6 \%$ versus $41 \cdot 3 \%$ in the balloon angioplasty group.

It is difficult to compare the results of the present study with data from non-randomised ELCA registries. ${ }^{68,16-18}$ Most of these registries focus attention on the initial results after laser angioplasty and have reported completeness of angiographic follow-up in $73-88 \%$ of patients after successful ELCA. In our trial, the clinical follow-up was complete in $98 \%$ of patients in both groups, and angiographic follow-up was complete in $93 \%$ of patients in the ELCA group and $91 \%$ of patients in the balloon angioplasty group. Furthermore, patients included in the registries had a variety of coronary lesions and the reported procedural success rates relate to those procedures in which the coronary lesion was successfully crossed with the guide wire. This explains why success rates in our study based on the intention-to-treat analysis are lower than in the ELCA registries, whereas results of the per protocol analysis are comparable to the registry data. Moreover, quantitative coronary analysis was performed by an independent core laboratory, whereas most angiographic results in the registries were based on visual assessment or semi-quantitative assessment. Finally, our trial, unlike the ELCA registries, included a routinely measured serum creatine kinase band level after each procedure.

A comparison of our balloon angioplasty group with randomised trials of balloon angioplasty shows similar results with respect to the clinical event rate and complication rate. ${ }^{23-26}$ However, there was a marked difference in our study in the procedural dissection rate observed in both treatment groups. The high incidence of dissections in our study might be related to selection of more complex coronary lesions compared with the other studies. ${ }^{5}$ Although the incidence of dissections was high, the majority of dissections were type $\mathrm{A}, \mathrm{B}$, or $\mathrm{C}$, which are benign.

The serum level of the creatine kinase myocardial band was systematically assessed in our trial. In this respect, the periprocedural myocardial infarction rate $(3 \cdot 2 \%)$, including $Q$ and non- $Q$-wave myocardial infarctions, cannot be compared with randomised balloon angioplasty studies. The incidence of myocardial infarctions is low compared with other studies in which the serum creatine kinase myocardial band level was evaluated after intracoronary interventions. These studies reported substantial increases in enzymes in $10-20 \%$ of procedures after balloon angioplasty or after application of other new devices such as directional atherectomy or coronary stenting..$^{27,28}$

This first randomised clinical trial of ELCA versus balloon angioplasty in obstructive coronary artery disease demonstrated no additional benefit of ELCA. Consequently, is there a role for ELCA in the treatment of coronary lesions? It is important to mention that the additional cost of ELCA favours the use of other treatments. Several modifications of the current laser technique are under investigation to optimise the results of intracoronary laser angioplasty. Adjustments in laser techniques to reduce formation of fast expanding and imploding vapour bubbles include a flushing protocol, ${ }^{29}$ application of sequential laser fibre activation, ${ }^{30}$ use of lower energy fluence, ${ }^{31}$ and use of a new laser catheter design in which homogeneous light distribution is provided.

The results of this trial demonstrate no additional benefit of ELCA over balloon angioplasty with the current laser technique.

Institutions participating in the AMRO study (number of patients enrolled): Academic Medical Center, University of Amsterdam, Netherlands (144); Thorax Center, Rotterdam, Netherlands (99); Catharina Hospital, Eindhoven, Netherlands (57); and Miami Heart Institute, Miami, Florida, USA (13).

Steering committee: J J Piek (chairman), Y E A Appelman, G K David, P J de Feyter, J J Koolen, P W Serruys, J G P Tijssen, S Strikwerda.

Safety monitoring committee: A Algra, C Borst, A V G Bruschke.

Critical event committee: J J Piek (chairman), G K David, P J de Feyter, J J Koolen, J G P Tijssen.

Data coordınating and analysis centre: Y E A Appelman, M J Koelemay, K Redekop, J G P Tijssen, G J Weverling, Academic Medical Centre, Department of Epidemiology and Biostatistics, Amsterdam.

Quantitative angiographic core laboratory: E W J Montauban v Swijndregt, E Nibbering, P W Serruys, Cardialysis, Rotterdam.

We thank Dr Martin J C van Gemert, Laser Center, Academic Medical Center, Amsterdam, and Dr René L H Sprangers, Academic Medical Center, Amsterdam, for their help during the initial phase of the AMROtrial; Dr Geert H M Gijsbers, Laser Center, Rotterdam, for his continuing support and helpful suggestions; and Prof A J Dunning, Department of Cardiology, Academic Medical Center, Amsterdam, and Prof J R T C Roelandt, Department of Cardiology, Dijkzigt Hospital, Rotterdam, for providing the facilities for completion of the AMRO-trial. Funded by the Dutch Health Insurance Executive Board.

\section{References}

1 Grundfest WS, Litvack IF, Goldenberg T, et al. Pulsed ultraviolet lasers and the potential for safe laser angioplasty. Am F Surg 1985; 150: 220-26.

2 Grundfest WS, Litvack F, Forrester JS, et al. Laser ablation of human atherosclerotic plaque without adjacent tissue injury. $\mathcal{F} \mathrm{Am}$ Coll Cardiol 1985; 5: 929-33.

3 Isner JM, Donaldson RF, Deckelbaum LI, et al. The excimer laser: gross, light microscopic and ultrastructural analysis of potential advantages for use in laser therapy of cardiovascular disease. $\mathcal{F} \mathrm{Am}$ Coll Cardiol 1985; 6: 1102-09.

4 Sartori M, Henry PD, Sauerbrey R, Tittel FK, Weilbaecher D, Roberts $\mathrm{R}$. 'Tissue interactions and measurement of ablation rates with ultraviolet and visible lasers in canine and human arteries. Lasers Surg Med 1987; 7: 300-06.

5 A report of the American College of Cardiology/American Heart Association Task Force on assessment of diagnostic and therapeutic cardiovascular procedures (subcommittee on percutaneous transluminal coronary angioplasty). Guidelines for percutaneous transluminal coronary angioplasty. Circulation 1988; 78: 486-502.

6 Bittl JA, Sanborn TA, Tcheng JE, Siegel RJ, Ellis SG. Clinical success, complications and restenosis rates with excimer laser coronary 
angioplasty. The percutaneous excimer laser coronary angioplasty registry. Am f Cardiol 1992; 70: 1533-39.

7 Margolis JR, Metha SM. Excimer laser coronary angioplasty. Am $\mathcal{f}$ Cardiol 1992; 69: 3F-11F.

8 Bittl JA, Sanborn TA. Excimer laser-facilitated coronary angioplasty relative risk analysis of acute and follow-up results in 200 patients. Circulation 1992; 86: 71-70.

9 Strikwerda S, Koolen JJ, De Feyter PJ, Sprangers RLH, Tijssen JGP, Serruys PW. Excimer laser coronary angioplasty in the Netherlands: preamble for a randomized study Am Heart F 1993; 125: 838-47.

10 The TIMI study group. The thrombolysis in myocardial infarction (TIMI) trial: phase I findings. $N$ Engl F Med 1985; 312: 932-36.

11 Stone GW, Rutherford BD, McConahay DR, et al. Procedural outcome of angioplasty for total coronary artery occlusion: an analysis of 971 lesions in 905 patients. 7 Am Coll Cardiol 1990; 15: 849-56.

12 Serrruys PW, Foley DP, de Feyter PJ, eds. Quantitative coronary angiography in clinical practice. Dordrecht, Netherlands: Kluwer Academic, 1994.

13 Cambeau L. Grading of angina pectoris. Circulation 1976; 54: 522-23.

14 Ellis SG, Vandormael MG, Cowley MJ, et al. Coronary morphologic and clinical determinants of procedural outcome with angioplasty for multivessel coronary disease. Circulation 1990; 82: 1193-1202.

15 Dorros G, Cowly MJH, Simpson J, et al. Percutaneous transluminal coronary angioplasty: report of complications from the National Heart, Lung, and Blood Institute PTCA registry. Circulation 1983; 76: 723-30.

16 Litvack F, Eigler N, Margolis J, et al. Percutaneous excimer laser coronary angioplasty: results in the first consecutive 3,000 patients. f Am Coll Cardiol 1994; 23: 323-29.

17 Baumbach A, Oswald H, Kvasnicka J, et al. Clinical results of coronary excimer laser angioplasty: report from the European coronary excimer laser angioplasty registry. Eur Heart f 1994; 15: 89-96.

18 Bittl JA, Kuntz RE, Estella P, Sanborn TA, Baim DS. Analysis of late lumen narrowing after excimer laser-facilitated coronary angioplasty. f Am Coll Cardiol 1994; 23: 1314-20.

19 Van Leeuwen TG, Van Erven L, Meertens JH, Motamedi M, Post MJ, Borst C. Origin of arterial wall dissections induced by pulsed excimer and mid-infrared laser ablation in the pig. $\mathcal{F} \mathrm{Am}$ Coll Cardiol 1992; 19: $1610-18$.
20 Van Leeuwen TG Meertens JH, Velema E, Post MJ, Borst C. Intraluminal vapour bubble induced by excimer laser pulse causes microsecond arterial dilatation and invagination leading to extensive wall damage in the rabbit. Circulation 1993; 3: 231-41.

21 Mintz GS, Pichard AD, Kent KM, Satler LF, Popma JJ, Leon MB. Intravascular ultrasound comparison of restenotic and de novo coronary artery narrowings. Am $\mathcal{F}$ Cardiol 1994; 74: $1278-80$.

22 Di Mario C, Gil R, Camenzind E, et al. Quantitative assessment with intracoronary ultrasound of the mechanisms of restenosis after percutaneous transluminal coronary angioplasty and directional; atherectomy. Am f Cardiol 1995; 75: 772-77.

23 Topol EJ, Leya F, Pinkerton CA, et al. A comparison of directional atherectomy with coronary angioplasty in patients with coronary artery disease. $N$ Engl F Med 1993; 329: 221-27.

24 RITA trial participants. Coronary angioplasty versus coronary artery bypass surgery: the Randomised Intervention Treatment of Angina (RITA) trial. Lancet 1993; 341: 573-80.

25 Serruys PW, Rutsch W, Heyndrickx GR, et al. Prevention of restenosis after percutaneous transluminal coronary angioplasty with thromboxane A2-receptor blockade. Circulation 1991; 84: 1568-80.

26 Serruys PW, Klein W, Tijssen JPG, et al. Evaluation of ketanserin in the prevention of restenosis after percutaneous transluminal coronary angioplasty. Circulation 1993; 88 (part 1): 1588-601.

27 Klein LW, Kramer BL, Howard E, Lesch M. Incidence and clinical significance of transient creatine kinase elevations and the diagnosis of non-Q wave myocardial infarction associated with coronary angioplasty. $\mathcal{f} \mathrm{Am}$ Coll Cardiol 1991; 17: 621-26.

28 Kugelmass AD, Cohen J, Moscuccie $M$, et al. Elevation of the creatine kinase myocardial isoform following otherwise successful directional coronary atherectomy and stenting. Am $\mathcal{F}$ Cardiol 1994; 74: 748-54.

29 Baumbach A, Haase KK, Rose C, Oberhoff M, Hanke H, Karsch KR. Formation of pressure waves during in vitro excimer laser irradiation in whole blood and the effect of dilution with contrast media and saline. Lasers Surg Med 1994; 14: 3-6.

30 Haase KK, Baumbach A, Spyridopoulos K, Oberhoff $M$, Karsch KR Initial clinical experience with a modified excimer laser for coronary angioplasty. Lasers Med Sci 1994; 9: 7-15.

31 Appelman YEA, Piek JJ, Verhoofstad GGAM, Gijsbers GHM, van Gemert MJC. Tissue ablation and gas formation of two excimer laser systems: an in vitro evaluation on porcine aorta Laser Surg Med (in press). 